\title{
A COMPARATIVE STUDY OF INCREASE IN CENTRAL CORNEAL THICKNESS FOLLOWING CONGENITAL CATARACT SURGERY IN CHILDREN
} \author{
Kannan Shalini ${ }^{6}$, Murugan $U_{m a}^{7}$ \\ ${ }_{1}^{1}$ Professor, Department of Ophthalmology, Madurai Medical College, Madurai. \\ ${ }^{2}$ Assistant Professor, Department of Ophthalmology, Madurai Medical College, Madurai. \\ 3 Junior Resident, Department of Ophthalmology, Madurai Medical College, Madurai. \\ 4 Junior Resident, Department of Ophthalmology, Madurai Medical College, Madurai. \\ 5 Junior Resident, Department of Ophthalmology, Madurai Medical College, Madurai. \\ 6Junior Resident, Department of Ophthalmology, Madurai Medical College, Madurai. \\ 7Junior Resident, Department of Ophthalmology, Madurai Medical College, Madurai.
}

Subbiah Vasan Chandrakumar ${ }^{1}$, Sooravali Ibrahim Thasneemsuraiya ${ }^{2}$, Anujoseph $^{3}$, Devadoss Sangeetha ${ }^{4}$, Ganesan Vidhubala ${ }^{5}$

\section{ABSTRACT}

\section{BACKGROUND}

The incidence rate of paediatric cataracts is high in developing countries like India ${ }^{1}$; about $7.4-15.3 \%$ of childhood blindness is due to congenital cataract. Although cataract extraction is performed at early ages in these children to prevent stimulus deprivation amblyopia, other complications such as secondary glaucoma, ${ }^{2}$ continue to threaten their long term visual outcome. It was observed that after congenital cataract extraction, the increase in central corneal thickness (CCT) leads to overestimation of Intraocular Pressure (IOP) by Goldman Applanation Tonometry (GAT); and hence overdiagnosis of glaucoma in operated children resulting in unnecessary use of antiglaucoma medications.

Aims and Objectives-

1) To determine the central corneal thickness in children following surgery for congenital cataract in primary/secondary pseudophakia and aphakia and compare with age-matched normal children.

2) To see the variation in central corneal thickness (CCT) following primary/secondary Posterior Chamber Intraocular Lens (PCIOL) implantation for congenital cataract.

\section{MATERIALS AND METHODS}

This is a descriptive comparative study conducted among children under 12 years of age who underwent surgery for congenital cataract, who attended the Outpatient Department (OPD) as well as wards of Department of Ophthalmology and/or Institute of Paediatrics at Government Rajaji Hospital, Madurai. The duration of study was 10 months. Subjects, who fulfilled all eligibility criteria, and none of the exclusion criteria, were only recruited in this study after obtaining written informed consent from their parents/guardian. Out of 170 eyes included in this study, 27 were aphakic, 74 were pseudophakic eyes (46 with primary intraocular lens implantation and 28 with secondary intraocular lens implantation) and 69 unoperated eyes in these subjects were taken as controls as preliminary CCT values were unavailable for the aphakic/pseudophakic eyes. A detailed evaluation of the anterior and posterior segment (dilated fundus examination) was done. Visual acuity was recorded in cooperative children. After explaining both the procedures; IOP \& CCT measurement; topical anaesthetic drops (0.5\% proparacaine) were instilled into the conjunctival sac. Intraocular pressure was recorded with GAT and in uncooperative children with Perkin's handheld Applanation tonometer. After 5 minutes, child is reassured and asked to fix at a distant target. CCT was measured using ultrasonic pachymeter by placing the tip of the probe gently on the centre of cornea. An average of 5 readings is taken. Uncooperative children were examined under oral sedatives. After IOP and CCT measurement, these were compared to the IOP and CCT readings of their corresponding age-matched healthy children.

\section{RESULTS}

The age distribution of cases and controls varied from 4 - 12 years. There was no significant difference in age between the study group and control group. Among the 85 children (170 eyes) studied, 52 were male and 33 were female. In the study group, total number of aphakic eyes was 27 and pseudophakic eyes 74. Among them, 46 had IOL implanted at the time of lens extraction (primary pseudophakia) while in 28 cases IOL was implanted on a later date (secondary pseudophakia). The CCT in aphakia group ranged from $540-620 \mu \mathrm{m}$, mean value being $597 \mu \mathrm{m}$. Maximum number of eyes had CCT in the range of $580-620 \mu \mathrm{m}$. The CCT in pseudophakic group ranged from $480-600 \mu \mathrm{m}$, mean value in primary pseudophakia being $514 \mu \mathrm{m}$ and for secondary pseudophakia it was $552 \mu \mathrm{m}$. The IOP values in the study group ranged between $12-32 \mathrm{~mm}$ of $\mathrm{Hg}$, the mean value is $22.88 \mathrm{~mm}$ of Hg. Among the 19 aphakic eyes studied, IOP varied from $12-32 \mathrm{~mm}$ of $\mathrm{Hg}$, mean value being $24 \mathrm{~mm}$ of $\mathrm{Hg}$. The IOP measurements in pseudophakic group ranged from $14-26 \mathrm{~mm}$ of $\mathrm{Hg}$, mean reading being $20 \mathrm{~mm}$ of $\mathrm{Hg}$. Corrected IOP values were determined in each study group as per Dresdner CCT - IOP correction table. For aphakics it was $22 \mathrm{~mm}$ of $\mathrm{Hg}$, primary pseudophakics $20 \mathrm{~mm}$ of $\mathrm{Hg}$ and secondary pseudophakics $20 \mathrm{~mm}$ of $\mathrm{Hg}$. There was a significant difference in CCT between the study group and control group. There was a significant positive correlation $(r=0.525)$ between CCT and IOP in the study group.

\section{CONCLUSION}

Children who have undergone lens extraction for congenital cataract are found to have a clinically significant increase in central corneal thickness which can in turn provide overestimated intraocular pressure readings by GAT. Aphakic eyes have a thicker 
cornea when compared to their pseudophakia counterpart. Measuring central corneal thickness and necessary intraocular pressure corrections should be made mandatory before prescribing anti-glaucoma medications in children who are highly susceptible to their serious side effects.

\section{KEYWORDS}

Congenital Cataract, Corneal Thickness, Aphakia.

HOW TO CITE THIS ARTICLE: Chandrakumar SV, Thasneemsuraiya SI, Anujoseph, et al. A comparative study of increase in central corneal thickness following congenital cataract surgery in children. J. Evolution Med. Dent. Sci. 2017;6(72):5142-5145, DOI: $10.14260 /$ jemds $/ 2017 / 1117$

Financial or Other, Competing Interest: None.

Submission 26-07-2017, Peer Review 24-08-2017,

Acceptance 30-08-2017, Published 07-09-2017.

Corresponding Author:

Dr. Sooravali Ibrahim Thasneem Suraiya

Eye Department OP No. 50,

Govt. Rajaji Hospital, No. 1

Panagal Road, Madurai-625020

Tamilnadu.

E-mail: eyedrck@gmail.com

DOI: $10.14260 /$ jemds $/ 2017 / 1117$

\section{(c) $(\mathbf{P})$}

\section{BACKGROUND}

The incidence rate of paediatric cataracts is high in developing countries like India; about $7.4-15.3 \%$ of childhood blindness is due to congenital cataract. Although cataract extraction is performed at early ages in these children to prevent stimulus deprivation amblyopia, other complications such as secondary glaucoma, continue to threaten their long term visual outcome. It was observed that after congenital cataract extraction, the increase in central corneal thickness (CCT) leads to overestimation of Intraocular Pressure (IOP) readings by Goldman Applanation Tonometry (GAT); and hence overdiagnosis of glaucoma in operated children resulting in unnecessary use of antiglaucoma medications.

\section{Aims and Objectives}

1. To determine the central corneal thickness in children following surgery for congenital cataract in primary/secondary pseudophakia and aphakia and compare with age-matched normal children.

2. To see the variation in central corneal thickness (CCT) following primary/secondary Posterior Chamber Intraocular Lens (PCIOL) implantation for congenital cataract.

\section{MATERIALS AND METHODS}

This is a descriptive comparative study conducted among children under 12 years of age who underwent surgery for congenital cataract, who attended the Outpatient Department (OPD) as well as wards of Department of Ophthalmology and or Institute of Paediatrics at Government Rajaji Hospital, Madurai, after obtaining written informed consent from their parents/guardian. The duration of study was 10 months. Those with previous history of ocular trauma, inflammatory ocular conditions, history of glaucoma drainage device surgery, any other associated congenital ocular anomalies, central corneal opacity or scar, history of refractive surgeries or penetrating keratoplasty and those with history of contact lens use, were excluded from this study.

The sample size was determined by our statistician using the formula $\mathrm{n}=\left(\mathrm{Z}_{\alpha / 2}+\mathrm{Z}_{\beta}\right)^{2 *}{ }^{*} \sigma^{2} / \mathrm{d}^{2}$, where ' $\mathrm{Z}_{\alpha / 2}$ ' - the critical value of the normal distribution at ' $\alpha / 2$ ' is $1.96,{ }^{\prime} \mathrm{Z} \beta$ ' - the critical value of the normal distribution at ' $\beta$ ' is 0.84, ' $\sigma$ ' - the population variance is 806 and ' $d$ ' - the difference we would detect is 21 . Henceforth, the sample size required for each group is 27 for confidence level 95\%, power $80 \%$, hypothesised difference is 10 and population 150 (very rare case). Out of 170 eyes included in this study, 27 were aphakic, 74 were pseudophakic eyes ( 46 with primary Intraocular lens implantation and 28 with secondary Intraocular lens implantation) and 69 unoperated eyes in these subjects were taken as controls as preliminary CCT values was unavailable for the aphakic / pseudophakic eyes.

A detailed evaluation of the anterior and posterior segment (dilated fundus examination) was done. Visual acuity was recorded in cooperative children. After explaining both the procedures - IOP \& CCT measurement, topical anaesthetic drops $(0.5 \%$ proparacaine $)$ instilled into the conjunctival sac. Intraocular pressure was recorded with GAT and in uncooperative children with Perkin's hand held Applanation tonometer. After 5 minutes, child is reassured and asked to fix at a distant target. CCT was measured using ultrasonic pachymeter by placing the tip of the probe gently on the centre of cornea. An average of 5 readings was taken. Uncooperative children were examined under oral sedatives (chloral hydrate syrup $25 \mathrm{mg} / \mathrm{kg}$ in 3 divided doses). After IOP and CCT measurement, these were compared to the IOP and CCT readings of their corresponding age-matched healthy children.

The information collected regarding all the cases were recorded in a Master Chart. Data analysis was done with the help of computer using Statistical Package for Social Sciences (SPSS) software developed by IBM corporation. Using this software- range, frequencies, percentages, means, standard deviations, ' $t$ ' value and ' $p$ ' values were calculated. Pearson correlation, Student's ' $t$ ' test was used to test the significance of difference between quantitative variables. A ' $p$ ' value of less than 0.05 is taken to denote significant relation.

\section{RESULTS}

The age distribution of cases and controls varied from 4 - 12 years, majority being in the range between 6 - 8 years of age. There was no significant difference in age between the study group and control group. Among the 85 children (170 eyes) studied, 52 were male and 33 were female. In the study group, total number of aphakic eyes was 27 and pseudophakic eyes 74 . Among the pseudophakic eyes, 46 had IOL implanted at the time of lens extraction (primary pseudophakia) while in 28 cases IOL was implanted on a later date (secondary pseudophakia). The age at which lensectomy was done in study group varied from 1 - 5 years, most of them being in the range of 2 - 3 years.

The central corneal thickness in aphakia group ranged from $540-620 \mu \mathrm{m}$, mean value being $597 \mu \mathrm{m}$. Maximum number of eyes had CCT in the range of $580-620 \mu \mathrm{m}$. The CCT in pseudophakic group ranged from $480-600 \mu \mathrm{m}$, mean 
value in primary pseudophakia being $514 \mu \mathrm{m}$ and for secondary pseudophakia it was $552 \mu \mathrm{m}$. Number of eyes in the study and control group belonging to various ranges of CCT (Table 1) was plotted; CCT was found to be higher in secondary pseudophakia when compared to their primary pseudophakia (Figure 1).

The IOP values in the study group ranged between 12 $32 \mathrm{~mm}$ of $\mathrm{Hg}$, the mean IOP being $23 \mathrm{~mm}$ of $\mathrm{Hg}$. Maximum number of eyes in study group had IOP in the range of $22-27$ $\mathrm{mm}$ of $\mathrm{Hg}$. Among the 19 aphakic eyes studied, IOP varied from $12-32 \mathrm{~mm}$ of $\mathrm{Hg}$, mean value being $24 \mathrm{~mm}$ of $\mathrm{Hg}$. The IOP measurements in pseudophakic group ranged from $14-$ $26 \mathrm{~mm}$ of $\mathrm{Hg}$, mean reading being $20 \mathrm{~mm}$ of $\mathrm{Hg}$. Corrected IOP values were determined in each study group as per Dresdner CCT - IOP correction table. For aphakics it was 22 $\mathrm{mm}$ of $\mathrm{Hg}$, primary pseudophakics $20 \mathrm{~mm}$ of $\mathrm{Hg}$ and secondary pseudophakics $20 \mathrm{~mm}$ of $\mathrm{Hg}$.

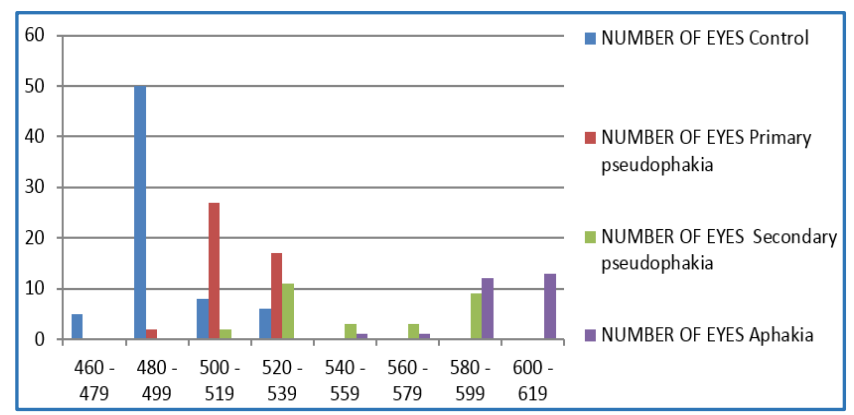

\section{Figure 1. The Colour Variation shows the Distribution of Cases based on CCT Values in Children: Maximum No Children in Control is in the CCT range of $480-499 \mu$ not seen in Aphakia and Increased CCT seen in Aphakia in the CCT range of 580-619 $\mu$ not seen in Control Group}

\begin{tabular}{|r|c|c|c|c|}
\hline \multirow{2}{*}{ CCT $(\boldsymbol{\mu m})$} & \multicolumn{4}{|c|}{ Number of Eyes } \\
\cline { 2 - 5 } & Control & $\begin{array}{c}\text { Primary } \\
\text { pseudophakia }\end{array}$ & $\begin{array}{c}\text { Secondary } \\
\text { pseudophakia }\end{array}$ & Aphakia \\
\hline $460-479$ & 5 & & & \\
\hline $480-499$ & 50 & 2 & & \\
\hline $500-519$ & 8 & 27 & 2 & \\
\hline $520-539$ & 6 & 17 & 11 & 1 \\
\hline $540-559$ & & & 3 & 12 \\
\hline $560-579$ & & & 9 & 13 \\
\hline $580-599$ & & & & 1 \\
\hline $600-619$ & \multicolumn{5}{|c|}{ Table 1. The Distribution of CCT Among Subjects in } \\
our study Showing the Increased CCT Among \\
Aphakia whereas CCT is low in Controls \\
\hline
\end{tabular}

The mean CCT was greater in study group than in control group. There was a significant difference in CCT between the study group and control group (' $p$ ' value $<0.001$ ). There was no significant relation between sex and CCT, age and CCT in study group. But a significant negative correlation was noted between age and CCT in control group (' $p$ ' value $<0.001$ ). As the age increases, CCT is found to decrease in normal healthy controls. There was a significant positive correlation ( $\mathrm{r}=$ 0.525 ) between CCT and IOP in the study group ("p" value < $0.001)$.

\begin{tabular}{|c|c|c|c|}
\hline PARAMETERS & MEAN & SD & “P” VALUE \\
\hline \multirow{2}{*}{$\begin{array}{c}\text { Control vs. } \\
\text { Aphakia }\end{array}$} & 492.967 & 15.092 & \multirow{2}{*}{$\begin{array}{c}<0.001 \\
\text { Significant }\end{array}$} \\
\hline & 596.500 & 16.262 & \\
\hline \multirow{2}{*}{$\begin{array}{c}\text { Control vs. } \\
\text { Primary } \\
\text { Pseudophakia }\end{array}$} & 492.967 & 15.092 & \multirow{2}{*}{$\begin{array}{c}<0.001 \\
\text { Significant }\end{array}$} \\
\hline & 514.833 & 11.429 & \\
\hline \multirow{2}{*}{$\begin{array}{c}\text { Control vs. } \\
\text { Secondary } \\
\text { Pseudophakia }\end{array}$} & 492.967 & 15.092 & \multirow{2}{*}{$\begin{array}{c}<0.001 \\
\text { Significant }\end{array}$} \\
\hline & 551.500 & 28.383 & \\
\hline \multirow{2}{*}{$\begin{array}{c}\text { Primary } \\
\text { Pseudophakia } \\
\text { vs. Aphakia }\end{array}$} & 514.833 & 11.429 & \multirow{2}{*}{$\begin{array}{c}<0.001 \\
\text { Significant }\end{array}$} \\
\hline & 596.500 & 16.262 & \\
\hline \multirow{2}{*}{$\begin{array}{c}\text { Secondary } \\
\text { Pseudophakia } \\
\text { vs. Aphakia }\end{array}$} & 551.500 & 28.383 & \multirow{2}{*}{$\begin{array}{c}<0.001 \\
\text { Significant }\end{array}$} \\
\hline & 596.500 & 16.262 & \\
\hline
\end{tabular}

Table 2. Table Showing Outcome of Statistical Analysis of Different Groups in Support of our Inferences

A similar correlation was found between the same variables in control group too (" $p$ " value $<0.001$ ). The difference in mean CCT values between aphakic eyes and primary pseudophakic eyes was more when compared to the difference between aphakic eyes and secondary pseudophakic eyes (Table 2). A significant difference was noted between CCT and IOP in both study group and control group with a "p" value of less than 0.001 .

\section{DISCUSSION}

The critical time period for developing amblyopia begins approximately at around 4 months of age. ${ }^{3}$ Segregation of ocular dominance and sensitivity of binocular correlation begins at 4 months of age. Hence, this is considered as the critical time period for visual development.

The normal anatomy of visual cortex is altered easily if sensory input is abnormal. Other areas of cerebral cortex also depend on this sensory input and stimulation, so as to form proper anatomical circuits essential for normal adult visual function. Most common clinical condition for stimulus deprivation amblyopia is congenital cataract ${ }^{4}$ or early acquired cataract. This fact underscores the significance of providing children with congenital cataract a timely intervention and equally important post-operative visual rehabilitation and follow-up. So removal of cataracts and clearing the obstruction to the visual axis at an earlier age should be done inevitably with adequate care given at the time of follow-up.

Since the children who have undergone cataract removal are highly susceptible to the risk of developing secondary glaucomas, a close monitoring of IOP and CCT changes should be done. This can be helpful in the management of this unique category of patients. There was a statistically significant increase in central corneal thickness in all eyes operated for congenital cataract. A longitudinal study conducted by Zena Lim and Kelly et $\mathrm{al}^{5}$ showed this increase in CCT was noticed in eyes without any evidence of glaucoma. They also found that mean CCT was even higher in eyes with aphakic or pseudophakic glaucoma.

A small case-control study on the endothelial characteristics in children who have undergone congenital cataract extraction did not show any significant changes in endothelial cell characteristics when compared to the age and sex-matched healthy control eyes, though there was a reduction in endothelial cell count. ${ }^{6}$ This finding is in contrast 
to the study done by Ramasubramanian et $\mathrm{al}^{7}$ who had the viewpoint that surgical trauma at the time of cataract extraction can cause endothelial cell dysfunction and resultant increase in CCT. Another school of thought for risk of developing glaucoma being more in aphakic group rather than in primary pseudophakia group is due to the exposure of the maturing angle structures and maturing cornea to harmful side effects of vitreous components. ${ }^{8}$ This access to trabecular meshwork and cornea is less if artificial lens is implanted at the same time as that of cataractous lens extraction. So, increased CCT in aphakia and pseudophakia eyes following congenital cataract extraction and its effect on IOP measurement should be borne in mind before making a diagnosis of glaucoma and prescribing anti-glaucoma medications in children.

\section{CONCLUSION}

Children who have undergone lens extraction for congenital cataract are found to have a clinically significant increase in central corneal thickness which can in turn provide overestimated intraocular pressure readings by GAT. Aphakic eyes have a thicker cornea when compared to their pseudophakia counterpart showing primary lens implantation can be a protective factor against this increase. Measuring central corneal thickness and necessary intraocular pressure corrections should be made mandatory before prescribing anti-glaucoma medications in children who are highly susceptible to their serious side effects.

\section{REFERENCES}

[1] Khokhar SK, Pillay G, Agarwal E, et al. Innovations in pediatric cataract surgery. Indian J Ophthalmol 2017;65(3):210-6.

[2] Simsek T, Mutluay AH, Elgin U, et al. Glaucoma and increased central corneal thickness in aphakic and pseudophakic patients after congenital cataract surgery. Br J Ophthalmol 2006;90(9):1103-6.

[3] Daw NW. Critical periods and amblyopia. Arch Ophthalmol 1998;116(4):502-5.

[4] Simsek T, Mutluay AH, Elgin U, et al. Glaucoma and increased central corneal thickness in aphakic and pseudophakic patients after congenital cataract surgery. Br J Ophthalmology 2006;90(9).

[5] Lim Z, Muir KW, Duncan L, et al. Acquired central corneal thickness increase following removal of childhood cataracts. Am J Ophthalmol 2011;151(3):434-41.

[6] Nilforushan N, Falavarjani KG, Razeghinejad MR, et al. Cataract surgery for congenital cataract: endothelial cell characteristics, corneal thickness, and impact on intraocular pressure. J AAPOS 2007;11(2):159-61.

[7] Ramasubramanian A, Mantagos I, Vanderveen DK. Corneal endothelial cell characteristics after pediatric cataract surgery. J Pediatr Ophthalmol Strabismus 2013;50(4):251-4.

[8] Faramarzi A, Feizi S, Maghsoodlou A. Factors influencing intraocular pressure, corneal thickness and corneal biomechanics after congenital cataract surgery. Br J Ophthalmol 2017. 